\title{
From land-use/land-cover to land system science
}

\author{
This article belongs to Ambio's 50th Anniversary Collection. Theme: Agricultural land use
}

\author{
B. L. Turner II, Eric F. Lambin, Peter H. Verburg
}

Published online: 13 March 2021

\section{INTRODUCTION}

Before transitioning to questions of sustainability, international research agendas addressing the Anthropocene focused on global environmental change, or the alterations in the structure and functioning of the earth system affected by human activity. Research focusing on terrestrial ecology recognized that projecting such changes into the future required an understanding of social-environment systems (SESs). Terrestrial ecological research, therefore, needed integration with social science research addressing the causes and projections of land uses-the purpose to which humankind employs the earth's surface-and land covera principal link to the biophysical subsystem. This integration generated the Land-Use and Land-Cover (LUCC) program on which the Turner et al. (1994) Ambio article was based.

Overall, this program focused on "cause-to-cover relationships" with the goal of informing various efforts to project forthcoming environmental changes from local to global scales. Recognizing the complexity of SESs, part of the program called for identifying large-scale cause-tocover situations (e.g., tropical deforestation or arid land degradation), developing a common research protocol, and generating systematic assessments of the situations to identify the major drivers of different land changes to improve future projections of them. Several meta-analyses of cause-to-cover change subsequently followed (e.g., Geist and Lambin 2002; Verburg et al. 2015). Systematic and analytically rich comparisons of the kind called for in the 1994 Ambio article did not, owing to funding constraints and new research questions and problems posed to the program by its parent organizations and revolving science committees.
The enlarged problem-set directed to land-use and cover subsequently gave rise to the Global Land Programme (GLP; now part of Future Earth) and a new field of study recognized as land system science (Verburg et al. 2015). This science engages a large range of research integrating the social and environmental sciences with strong links to the remote sensing and geographical information sciences, and to various modeling approaches. Land system science seeks to integrate these interests through the lens of SESs to address (1) why, how, where human activity, locally to globally, affects the terrestrial surface and (2) the consequences of the impacts, especially for sustainability issues, and to assist (3) in projecting land-use and -cover changes and their consequences in the near-term future. In addition, land system science has added the urban category to its land inventory, addressing the implications of urban sustainability through land-use and -cover dynamics (e.g., Seto et al. 2012). Here we trace some of the major advances in land system science and the challenges it faces.

\section{CAUSES}

Over the last few decades, the land system science community has conducted a large number of detailed case studies documenting and explaining land-use changes across all biomes and continents, save Antarctica, even delving into the examination of the motivations of landchange actors (e.g., Rueda et al. 2019). Such effort has been accompanied by several meta-analyses that have searched for generalizable patterns of causes leading to tropical deforestation, reforestation, dryland degradation, agricultural intensification, and urbanization, among other 
efforts (van Vliet et al. 2016). Several typical pathways of land-use change have been uncovered, many of them specific to a region and a time period. For example, while the immediate cause of tropical deforestation was once largely associated with smallholder colonization of forest frontiers, by about 2000, the production of export commodity crops (e.g., palm oil, soy, beef) by "largeholders" accounted for an increasingly large fraction of this deforestation, either directly or indirectly by pushing smallholders into the frontier. This and other pathways of landuse change typically involve multiple interacting causes operating from the local to global scales. The complexity of these causes, as well as individuality of the studies identifying them, has made high-level generalizations of generic causal pathways difficult to determine.

Land-use and -cover changes also involve social-environment (or human-environment) system dynamics that can lead to rapid use transitions, ecological regime shifts, and distant impacts. For example, forest transitions-national scale shifts from net deforestation to net reforestation-may occur abruptly owing to various combinations of the growth in off-farm employment, forest scarcity, state intervention or its loss in land management, land-use diversification by smallholders, and integration in the global economic system (Rudel et al. 2020). Depending on the exact factors at play, the increase in forest cover can be dominated by natural forest regeneration or by tree plantations-often monocultures of exotic species-with different impacts on the ecological value of the new landcover, its functioning, and the ecosystem services generated. More often than not, forest transitions include some "off-shoring" of land use elsewhere to import forest and agricultural products lost with the gain in forest cover. Recent studies have quantified the linkages between trade in land-based commodities and land use, highlighting the mechanisms through which consumption and land-use restrictions in one place affect land use in distant places (Pendrill et al. 2019), which has been termed "telecoupling".

\section{REMOTE SENSING}

Major advances have been made in the use of remote sensing and ancillary data and methods to detect land conditions and their change, including the fine-grain specification of land covers and the quantification of rates and patterns of change. These advances follow from new sensors, improved spatial and temporal satellite data, the development of "big data" and artificial intelligence methods to extract information, and sustained experimentation with various data and methods to gain new insights of land systems. As a result, forest cover changes, cropland expansion and intensification, and changes in urban areas and forms can be mapped and quantified anew. By contrast, land degradation, which is a more multifaceted form of land-cover change, remains poorly quantified.

The large fraction of the land surface that either has been converted or modified by human use has been determined. We can monitor the rates of different land changes regionally and globally, and better estimate the past history of those changes (e.g., Song et al. 2018). Use of aerial remote sensing data, including laser imaging, detection and ranging, and spectroscopy, has improved calculations of tropical forest carbon storage, helped to estimate the number of trees in the world, and address a large range of topics from forest speciation and invasive species to drought impacts (e.g., Asner et al. 2008, 2016). Novel combinations of methods and remote sensing have even been used to identify illicit activities, including that on tropical forest loss based on anomalies in the patterns of deforestation (Tellman et al. 2020). The availability of remote sensing data at very fine spatial resolutions coupled with household-level socio-economic data have revealed multiple patterns of interactions between land managers and terrestrial ecosystems, illuminating important debates on, for example, reconciling food security with nature conservation, whether through land sparing, land sharing, or sustainable intensification strategies.

\section{MODELLING}

Modelling continuous to be a tool to integrate understanding of land system change and provide exploration of future scenarios or assessment of policy alternatives (Verburg et al. 2016). Land system models have evolved from pattern-based modelling to including a higher level of understanding of decision-making processes in land-use change. The recognition that land-use change is caused by decisions of individual or collective agents gave rise to the development of agent-based models in which land system decisions are based on the response of agents to large-scale drivers and their socio-environmental context. Heterogeneity of decision-making, given the abilities and willingness of the agents, is explicitly addressed. Such models provide formalized tools to explore the roles of different actors on land system changes and the ways in which heterogeneity in decision-making gives rise to variations in the landscape. To operationalize such models, in-depth behavioral research on decision-making is linked to spatial data, thereby providing a platform for integration of insights from different perspectives. Most applications are focused on the local to regional level and address casestudy contexts (O'Sullivan et al. 2016). Land-use models underlying major global assessments, such as those 
employed by the intergovernmental panels and platforms on climate change and biodiversity and ecosystems, do not yet include agency and remain based on basic macro-economic and biophysical suitability-based assumptions, which limits their realism and actionability. While any large-scale modelling requires generalization, new global synthesis of different modes of land-use decision-making (Malek et al. 2019) and middle-range theory (Meyfroidt et al. 2018) can help to better account for agency and land system processes in global assessments.

\section{INTEGRATION}

In the formation of the international Global Land Programme (GLP), social and natural systems were treated much more as separate systems. Over the thirty years of the development of land system and related sciences, various approaches attempt to treat the two subsystems in a more integrated way. While true social-environmental theory has yet to emerge (below), models increasingly link the impacts and feedbacks between components of the two subsystems at multiple scales. These cross-scale dynamics linking land-use decision-making by local actors to, for example, landscape-scale biophysical processes, nationalscale policies, and global-scale supply chains is a key challenge in the understanding and prediction of land-use changes. In addition, land system science has become increasingly interdisciplinary, using a wide portfolio of complementary methods approaches. Qualitative studies inform quantitative assessment to translate contextual findings to generic patterns and provide input that informs models and theory development (Manson and Evans 2007). This progress permits important issues related to land tenure and land governance, which largely have been ignored in past quantitative approaches, to be addressed. One example of such blending of approaches from different disciplinary backgrounds is model development using participatory approaches for parameterization and testing.

\section{SUSTAINABILITY}

Initially land-use change was viewed by the parent programs of LUCC as an effort directed primarily to understanding the causes of global environmental change. Today a generic understanding exists that land use is part of a solution to global environmental change and sustainability problems, with tradeoffs between social and environmental subsystems, for example, biodiversity conservation and food security. Increasing attention in the GLP and land system science is given to understanding how various policy interventions affect land use, whether these interventions are designed and implemented by public or private actors, embedded within command-and-control or based on incentives, or employed as area-based or supply chain interventions. Over the years, a large portfolio of tools has become available to support policy design and evaluation (e.g., Jayachandran et al. 2017). Apart from exante assessment tools that model the land change consequences of policy interventions, these also include tools that help trace the links between consumers and distant land-use impacts through supply chains, helping to allocate impacts associated with consumption patterns or the benefits of specific certification programs (Green et al. 2019). Others combine Life Cycle Assessment with land use analysis to address supply chain global connections (Chaplin-Kramer et al. 2017). Optimization or prioritization tools help to target policy interventions to areas where impacts of interventions may be most effective, or minimize tradeoffs between functions of the land systems (Verhagen et al. 2018). These top-down, computational tools are complemented by the advances in landscape approaches, in which co-design of interventions is based on participation of local stakeholders (Carmenta et al. 2020). Bringing the top-down allocation and the bottom-up engagement in land system policy interventions together is needed for effective implementation.

\section{CHALLENGES}

Perhaps the ultimate challenge for land system science, as for all SES-based sciences, is the development of a general theory to guide understanding of land-use and land-cover change. It is noteworthy that the social subsystem-land use-has a plethora of specific theories examined in detail (Meyfroidt et al. 2018), but has yet to develop a general theory inclusive to a large range of land uses. This development has been frustrated, as noted above, by the complexity of land systems and the absence, to date, of systematic, comparative assessments of the range of land system explanations, as initially called for in the early development of the international science agenda on land use (Turner et al. 1994). Given the advances in understanding land uses and systems, the broader community of researchers may be poised to undertake the exploration in question (Turner et al. 2020).

Finally, land system science as a whole has yet to synthesize its evidence and understanding to tackle directly the various land-based "solutions" emanating from international programs addressing environmental change and sustainability. Examples of such solutions include increased protection of natural areas to halt further biodiversity losses; afforestation, reforestation, soil management or biomass cultivation for climate change mitigation; or 
increased agricultural production to secure food. In contrast, individual land system researchers have been involved in agendas dealing with the assessments of actions that might be taken on land degradation, climate change, biodiversity, food provisioning, and other such topics. As all these "solutions" make use of the same, limited land resources, the land system science community at large can address how these "solutions" interact and lead to synergetic benefits or competing claims. Land system science is making significant input to these topics.

\section{REFERENCES}

Asner, G.P., D.E. Knapp, T. Kennedy-Bowdoin, M.O. Jones, R.E. Martin, J. Boardman, and R.F. Hughes. 2008. Invasive species detection in Hawaiian rainforests using airborne imaging spectroscopy and LiDAR. Remote Sensing of Environment 112: 1942-1955.

Asner, G.P., P.G. Brodrick, C.B. Anderson, N. Vaughn, D.E. Knapp, and R.E. Martin. 2016. Progressive forest canopy water loss during the 2012-2015 California drought. Proceedings of the National Academy of Sciences 113: 249-255.

Carmenta, R., D.A. Coomes, F.A.J. DeClerck, A.K. Hart, C.A. Harvey, J. Milder, J. Reed, B. Vira, et al. 2020. Characterizing and evaluating integrated landscape initiatives. One Earth 2: 174-187.

Chaplin-Kramer, R., S. Sim, P. Hamel, B. Bryant, R. Noe, C. Mueller, G. Rigarlsford, M. Kulak, et al. 2017. Life cycle assessment needs predictive spatial modelling for biodiversity and ecosystem services. Nature Communications 8: 15065.

Geist, H.J., and E.F. Lambin. 2002. Proximate causes and underlying driving forces of tropical deforestation. Bioscience 52: 143-150.

Green, J.M.H., S.A. Croft, A.P. Durán, A.P. Balmford, N.D. Burgess, S. Fick, T.A. Gardner, J. Godar, et al. 2019. Linking global drivers of agricultural trade to on-the-ground impacts on biodiversity. Proceedings of the National Academy of Sciences 116: 23202-23208.

Jayachandran, S., J. de Laat, E.F. Lambin, C. Stanton, R. Audy, and N. Thomas. 2017. Cash for carbon: A randomized controlled trial of payments for ecosystem services to reduce deforestation. Science 357: 267-273.

Malek, Ž., B. Douw, J. Van Vliet, E.H. Van Der Zanden, and P.H. Verburg. 2019. Local land-use decision-making in a global context. Environmental Research Letters 14: 083006.

Manson, S.M., and T. Evans. 2007. Agent-based modeling of deforestation in southern Yucatan, Mexico, and reforestation in the Midwest United States. Proceedings of the National Academy of Sciences 104: 20678-20683.

Meyfroidt, P., R. Roy Chowdhury, A. De Bremond, E.C. Ellis, K.-H. Erb, T. Filatova, R.D. Garrett, J.M. Grove, et al. 2018. Middlerange theories of land system change. Global Environmental Change 53: 52-67.

O'Sullivan, D., T. Evans, S. Manson, S. Metcalf, A. LigmannZielinska, and C. Bone. 2016. Strategic directions for agentbased modeling: Avoiding the YAAWN syndrome. Journal of Land Use Science 11: 177-187.

Pendrill, F., M. Persson, J. Godar, and T. Kastner. 2019. Deforestation displaced: Trade in forest-risk commodities and the prospects for a global forest transition. Environmental Research Letters. https://doi.org/10.1088/1748-9326/ab0d41.
Rueda, X., M.A. Velez, L. Moros, and L. Rodriguez. 2019. Beyond proximate and distal causes of land-use change: Linking Individual motivations to deforestation in rural contexts. Ecology and Society 24 (1): 4. https://doi.org/10.5751/ES-10617-240104.

Rudel, T.K., P. Meyfroidt, R. Chazdon, F. Bongers, S. Sloan, H.R Grau, T. Van Holt, and L. Schneider. 2020. Whither the forest transition? Climate change, policy responses, and redistributed forests in the twenty-first century. Ambio 49: 74-84. https://doi. org/10.1007/s13280-018-01143-0.

Seto, K.C., A. Reenberg, C.G. Boone, M. Fragkias, D. Haase, T. Langanke, P. Marcotullio, D.K. Munroe, et al. 2012. Urban land teleconnections and sustainability. Proceedings of the National Academy of Sciences 109: 7687-7692.

Song, X.P., M.C. Hansen, S.V. Stehman, P.V. Potapov, A. Tyukavina, E.F. Vermote, and J.R. Townshend. 2018. Global land change from 1982 to 2016. Nature 560: 639-643.

Tellman, B., N.R. Magliocca, B.L. Turner II, and P.H. Verburg. 2020. Understanding the role of illicit transactions in land-change dynamics. Nature Sustainability 3: 1-7.

Turner II, B.L., W.B. Meyer, and D.L. Skole. 1994. Global landuse/land-cover change: Towards an integrated study. Ambio 23: 91-95.

Turner II, B.L., P. Meyfroidt, T. Kuemmerle, D. Müller, and R. Roy Chowdhury. 2020. Framing the search for a theory of land use. Journal of Land Use Science 15 (4): 489-508.

van Vliet, J., N.R. Magliocca, B. Büchner, E. Cook, J.M. Rey Benayas, E.C. Ellis, A. Heinimann, E. Keys, et al. 2016. Metastudies in land use science: Current coverage and prospects. Ambio 45: 15-28. https://doi.org/10.1007/s13280-015-0699-8.

Verhagen, W., E.H. van der Zanden, M. Strauch, A.J.A. van Teeffelen, and P.H. Verburg. 2018. Optimizing the allocation of agri-environment measures to navigate the trade-offs between ecosystem services, biodiversity and agricultural production. Environmental Science \& Policy 84: 186-196.

Verburg, P.H., N. Crossman, E.C. Ellis, A. Heinimann, P. Hostert, O. Mertz, H. Nagendra, T. Sikor, et al. 2015. Land system science and sustainable development of the earth system: A global land project perspective. Anthropocene 12: 29-41.

Verburg, P.H., J.A. Dearing, D.J. Dyke, S. van der Leeuw, S. Seitzinger, W. Steffen, and J. Syvitski. 2016. Methods and approaches to modelling the Anthropocene. Global Environmental Change 39: 328-340.

Publisher's Note Springer Nature remains neutral with regard to jurisdictional claims in published maps and institutional affiliations.

\section{B. L. Turner II ( $\square)$}

Address: School of Geographical Sciences and Urban Planning \& School of Sustainability, Arizona State University, P.O. Box 875302, Tempe, AZ 85287-5302, USA.

e-mail: billie.1.turner@asu.edu

\section{Eric F. Lambin}

Address: School of Earth, Energy \& Environment Sciences and Woods Institute for the Environment, Stanford University, $473 \mathrm{Via}$ Ortega, Stanford, CA 94305, USA.

Address: Georges Lemaitre Earth and Climate Research Centre, Earth and Life Institute, Université catholique de Louvain, 3 place Pasteur, 1348 Louvain-la-Neuve, Belgium.

\section{Peter H. Verburg}

Address: Institute for Environmental Studies, VU University Amsterdam, de Boelelaan 1111, 1081HV Amsterdam, The Netherlands. 